Open Access

Original Article

\title{
Transcanalicular diode laser assisted dacryocystorhinostomy: A breakthrough in the treatment of acquired nasolacrimal duct obstruction
}

\author{
Muhammad Awais', Syed Abid Hassan Naqvi², \\ Amjad Akram $^{3}$, Muhammad Shahid ${ }^{4}$
}

\begin{abstract}
Objective: To evaluate the success rate of Transcanalicular Diode laser assisted Dacryocystorhinostomy (TC-DCR) in cases of acquired nasolacrimal duct obstruction (NLDO).

Methods: This Quasi-Experimental study was conducted in Armed Forces Institute of Ophthalmology (AFIO) Rawalpindi, from July 2018 to April 2019. In this study, 73 patients of chronic dacryocystitis secondary to acquired NLDO were treated by TC-DCR under general anaesthesia. Follow up examination was done after one day, one week and three months. Silicone tubes were removed three months after surgery and syringing of lacrimal system done to confirm patency of lacrimal passages. Success of the procedure was documented as absence of epiphora and patent nasolacrimal duct on syringing.

Results: Seventy three patients (males 27; females 46) were included in this study. Mean age of these patients was $51.6 \pm 21$ years. On completion of this study which was three months after surgery, we found subjective improvement (absence of epiphora) in $86.3 \%$ patients and objective improvement (successful irrigation of lacrimal passages) in $93.2 \%$ patients.

Conclusion: TC- DCR is a minimally invasive technique of doing Dacryocystorhinostomy and imparts more than $90 \%$ success rate. It has additional advantages of good cosmetic results, low complication rate and short surgery and convalescence time.
\end{abstract}

KEYWORDS: Epiphora, Transcanalicular Dacryocystorhinostomy, Diode laser.

How to cite this:

doi: https://doi.org/10.12669/pjms.36.4.1906

Awais M, Naqvi SAH, Akram A, Shahid M. Transcanalicular diode laser assisted dacryocystorhinostomy: A breakthrough in the treatment of acquired nasolacrimal duct obstruction. Pak J Med Sci. 2020;36(4):804-807. doi: https://doi.org/10.12669/pjms.36.4.1906

This is an Open Access article distributed under the terms of the Creative Commons Attribution License (http://creativecommons.org/licenses/by/3.0), which permits unrestricted use, distribution, and reproduction in any medium, provided the original work is properly cited.

\section{INTRODUCTION}

1. Dr. Muhammad Awais, FCPS (Ophth)

2. Dr. Syed Abid Hassan Naqvi, FCPS (Ophth), FRCS.

3. Dr. Amjad Akram, FCPS. FRCS (Glasgow), FRCS (Ed.)

4. Dr. Muhammad Shahid, FCPS (Ophth)

1-4: Armed Forces Institute of Ophthalmology (AFIO) Rawalpindi, Rawalpindi - Pakistan.

Correspondence:

Dr. Muhammad Awais, FCPS.

Consultant Ophthalmologist,

Armed Forces Institute of Ophthalmology (AFIO),

Mall Road, Saddar,

Rawalpindi, Pakistan.

Email: awaisamc@gmail.com

* Received for Publication:

October 3, 2019

* Accepted for Publication:
March 3, 2020
Chronic dacryocystitis is chronic inflammation of lacrimal sac and its most common cause is occlusion of nasolacrimal duct. ${ }^{1}$ If untreated, it may cause recurrent conjunctival inflammation, ${ }^{2}$ dacryocoele, lacrimal sac fistula and even orbital cellulitis. Treatment of choice for chronic dacryocystitis is dacryocystorhinostomy (DCR) in which a permanent passage is created between lacrimal sac and nasal cavity. DCR through external approach, due to high success rate (>90\%) remained the gold standard technique for decades. ${ }^{3}$ Caldwell in 1893 described an alternative to DCR by doing it via endonasal approach with the help of nasal endoscope. ${ }^{3}$ Later on, because of the innovation 
of higher resolution fiber optic nasal endoscopes, endoscopic DCR started becoming popular. The recent advancement in DCR technique is doing it via transcanalicular approach, in which osteotomy is created with the help of diode laser. ${ }^{4}$ Diode laser assisted TC-DCR has some additive advantages as it can be done under local anesthesia, causes precise cutting and removal of tissue by ablation, is bloodless, less time-consuming, leaves no external scars and can be repeated. ${ }^{5,6}$ It can also be used to treat failed Ex-DCR.

Diode laser-assisted TC-DCR has become the topic of several current papers internationally. But the literature search showed that no study has, so far, been conducted on Pakistani population, in this regard. The rationale of doing this study was to determine and publish the success rate of diode laser assisted TC-DCR in Pakistani patients of primary acquired NLDO.

\section{METHODS}

This Quasi-experimental study comprises 73 Patients who underwent diode laser assisted TCDCR between July 2018 and April 2019. Approval for the study was granted by the Institutional Review Board. Patients of chronic dacryocystitis secondary to primary acquired NLDO were included in the study. The exclusion criteria included acute dacryocystitis, common canalicular obstruction, severe facial trauma causing disfigurement and nasal polyp. Patients reporting in the OPD of AFIO, with the complaint of epiphora were examined and those with the problems of puntal stenosis, allergic conjunctivitis, blepharitis, dry eyes, corneal or conjunctival infections were excluded. After screening, these patients underwent syringing and lacrimal irrigation and patients with blocked nasolacrimal duct were selected for the surgical procedure. Written informed consent was obtained from these patients. Pre-operative anaesthesia assessment of these patients was done by a consultant anaesthetist. Endoscopic nasal examination of these paients was done to exclude deviated nasal septum or nasal polyps. For TC-DCR procedure, we used KLS Martin DiomaX machine. Our preferred settings are three Watt power in pulse mode, pulse duration two sec, pause between pulses $0.4 \mathrm{sec}$, and so average power is 2.5 watt. The laser was delivered through 600 um flexible fibre optic probes.

We performed all the cases under general anaesthesia. Nasal packing was done with neuro patties (ribbon gauze) soaked in a solution containing lignocaine and adrenaline in 1: 10,000 ratio. A solution of epinephrine 1: 100,000 was infiltrated into nasal mucosa of lateral nasal wall so that per operative bleeding may be minimized. Both upper and lower puncta were dilated and a bowman lacrimal probe was passed to feel hard stop. Fiber optic laser probe was passed through one punctum into the lacrimal sac. Zero degree nasal video endoscope was introduced into the respective nasal cavity and the red beam translucency of laser probe was seen in the nasal cavity. The site of osteotomy in this procedure is just anterior and inferior to the attachment of middle nasal concha to the lateral nasal wall. Tip of the Diode laser probe was in direct contact with the medial wall of lacrimal sac. Then the laser was fired repeatedly which ablated lacrimal sac tissue, lacrimal bone and nasal mucosa and thus created an opening. This osteotomy was then enlarged to about five $\mathrm{mm}$ by applying adjacent burns. Bicanalicular silicone tubes were passed through the punta and retrieved through nostril and tied in the nasal cavity. Post operatively, nasal cavity was packed using ribbon gauze soaked in a solution of two percent lignocaine with adrenaline to minimize bleeding from nasal mucosa. This nasal packing was removed next morning. Patients were prescribed Tab Amoxycillin-Clavulanic acid, one gram 12 hourly and Tab Paracetamol 500 mg 12 hourly for three days. Tobramycin plus dexamethasone eye drops were prescribed four times daily for one month. Oxymetazoline nasal spray was prescribed to use, eight hourly, daily for two weeks. Followup visits were scheduled on one day, one week and then three months after surgery. After three months of surgery, silicone tubes were removed and all the patients underwent lacrimal syringing to confirm patency of the lacrimal system. Success of the procedure was determined as absence of epiphora/discharge and patent nasolacrimal duct on irrigation.

Variables like age, gender, post- operative epiphora and post-operative regurgitation were noted. Statistical package for social sciences (SPSS 25) was used for statistical analysis.

\section{RESULTS}

Seventy three patients underwent diode laser assisted TC-DCR. Out of these, 27 (37\%) were males and $46(63 \%)$ females. Mean age of these patients was $51.6 \pm 21$ years. Thirty nine cases were of right NLDO whereas 33 cases were of left NLDO. One patient underwent bilateral DCR. We divided parameters of success (lacrimal patency) into subjective (absence of epiphora) and objective (successful irrigation of lacrimal passages) ones. 
Table-I: Crosstabulation between gender and post-operative epiphora and post- op regurgitation.

\begin{tabular}{lcccc}
\hline \multirow{2}{*}{ Gender } & \multicolumn{2}{c}{ Post Op Epiphora } & \multicolumn{2}{c}{ Post Op Regurgitation } \\
\cline { 2 - 5 } & Yes & No & Yes & No \\
\hline Male & $8(80.0 \%)$ & $19(30.2 \%)$ & $3(60.0 \%)$ & $24(35.3 \%)$ \\
Female & $2(20.0 \%)$ & $44(69.8 \%)$ & $2(40.0 \%)$ & $44(64.7 \%)$ \\
\hline
\end{tabular}

We found absence of epiphora in 63 (86.3\%) patients whereas $10(13.7 \%)$ patients complained of persistent watery discharge three months after surgery. Post-operative epiphora occurred in eight $(80 \%)$ males and two (20\%) females (Table-I); $\mathrm{p}$-value is 0.002 which is significant. On irrigation of lacrimal passage, we found objective improvement in $68(93.2 \%)$ patients. In these patients, saline jet injected through punctum reached pharynx. Saline jet regurgitated back only in five $(6.8 \%)$ patients. Post-operative regurgitation occurred in three $(60 \%)$ males and two (40\%) females (Table-I); $\mathrm{p}$-value is 0.269 which is not significant. Anatomical success rate in our patients after transcanalicular diode laser assisted DCR was $93.2 \%$.

\section{DISCUSSION}

The modern era aims and strives for least traumatic surgical procedures which impart good cosmetic results, and early post-operative recovery. Ophthalmology is no stranger to this. External Dacryocystorhinostomy (Ex DCR) was previously considered the gold standard technique for the treatment of chronic dacryocystitis. ${ }^{7}$ Though it yielded good anatomical and functional success, the issues of cutaneous scar, prolonged procedure time and per operative bleeding could not be addressed. Dacryocystorhinostomy via endonasal approach was also not devoid of the issues of per-operative bleeding and long learning curve.

Transcanalicular laser assisted DCR (TC-DCR) is a minimally invasive alternative to Ex DCR. ${ }^{8,9}$ The obvious advantages of avoiding an external incision $^{10}$ and fast post-operative recovery made it attractive to many patients. ${ }^{6}$ Short learning curve, less procedure time, ${ }^{11}$ minimal per-operative bleeding during TC-DCR is gaining attention of ophthalmologists. This procedure can be used for revision of failed Ex DCR. It can be performed under local anaesthesia and can protect the patients from the risks of general anaesthesia. ${ }^{12}$ Lasers with several wavelengths have been used to perform osteotomy; some of these are Holmium:Yttrium-Aluminum-
Garnet (Ho:YAG) laser, Neodymium:YAG (Nd:YAG) laser, Erbium:YAG (Er:YAG) laser and Diode laser. ${ }^{11}$ Diode laser has some peculiar advantages over other laser types. For example, this is a contact laser and the energy emitted is confined to the tip of laser probe. Secondly presence of an insulating sleeve around the probe minimizes collateral heating. It also achieves effective tissue dissection, precise cutting and removal of tissue by ablation resulting in minimal haemorrhage and improved intraoperative view. ${ }^{1}$

In this prospective study, we performed TC-DCR on 73 patients out of which $27(37 \%)$ were males and $46(63 \%)$ were females. Lacrimal sac problems are found more common in females. ${ }^{13,14}$ In a study conducted by Al-Asaadi SZ, the male patients were $31.35 \%$ while the females were $68.75 \% .^{15}$ This is close to our results. Lacrimal passageway was open in $93.2 \%$ of our operated patients three months after surgery. Our results are close to that of Ex DCR (90$95 \%) .{ }^{16}$ This high success rate is attributed to few factors. The operating surgeon was quite familiar with the nasal anatomy and made adequate sized osteotomy by visualizing through nasal endoscope. The use of silicone tubes also enhanced our success rate. Because of Diode laser, minimal trauma occurred to the surrounding tissue leading to minimal post- operative inflammation and scarring at osteotomy site which also reduced chances of procedure failure. However, results of TC- DCR are quite variable in published literature. Brigita Drnovsek-Olup reported success rate of $83.3 \% .{ }^{11}$ Salah Zuhair Al-Asadi reported success rate of 93.75\% after performing TC-DCR with silicone intubation. ${ }^{15}$ Success rate of $90 \%$ is reported by Goel R et al. ${ }^{1}$ A functional success rate of $74-85 \%$ is also reported at one year follow-up. ${ }^{6,11,17-21}$ But contrary to above, Kaynak et al. reported that the success rate of TC-DCR drops to $60 \%$ within two years. ${ }^{22}$ The differences in success rates are probably because of use of different laser settings by different people, preference of silicone intubation, local vs general anaesthesia and use of adjunctive antimetabolites like Mitomycin C at osteotomy site. To improve success rate, most important step is the correct formation of an adequate sized osteotomy at the optimal location. ${ }^{23,24}$ It is better to aim for as big an osteotomy as possible while at the same time avoiding unnecessary tissue damage. A limitation of this study was its shorter follow-up period. Concerns are about long-term success of TC-DCR. Hence, further studies need to be conducted with long-term follow-up. 


\section{CONCLUSION}

Transcanalicular laser-assisted DCR provides good results and is a viable option before proceeding to more invasive lacrimal surgery in cases of nasolacrimal duct obstruction. Because of low complication rates and short convalescence and surgery time, patient satisfaction is high. While at the same time, functional success rates range closely behind those of external DCR.

Conflict of Interest: No conflict of Interest.

Financial Disclosure: Nil.

\section{REFERENCES}

1. Goel R, Nagpal S, Kumar S, Meher R, Kamal S, Garg S. Transcanalicular Laser-Assisted Dacryocystorhinostomy with Endonasal Augmentation in Primary Nasolacrimal Duct Obstruction: Our Experience. Ophthalmic Plast Reconstr Surg. 2017;33(6):408-412. doi: 10.1097/ IOP.0000000000000802

2. Williams B, Johnson D, Hurst J, Kratky V. Patterns and causes of epiphora referrals to a tertiary oculoplastic practice. Can J Ophthalmol 2014;49:180-182. doi: 10.1016/j. jcjo.2013.12.003

3. Mourya D, Rijal RK. Transcanalicular laser assisted dacryocystorhinostomy with diode laser. Orbit 2017;36(6):370-374. doi: 10.1080/01676830.2017.1337189

4. Maeso Riera J, Sellarès Fabrés MT. Transcanalicular dacryocystorhinostomy with diode laser: Technical variations and results. Acta Otorrinolaringol Esp. 2007;58:10-15.

5. Mor JM, Guo Y, Koch KR, Heindl LM. Transcanalicular Diode Laser aassisted Dacryocystorhinostomy for the Treatment of Primary Acquired Nasolacrimal Duct Obstruction. J Vis Exp. 2017;13:128. doi: 10.3791/55981

6. Koch KR, Kühner H, Cursiefen C, Heindl LM. Significance of transcanalicular laser assisted dacryocystorhinostomy in modern lacrimal drainage surgery. Ophthalmologe. 2015;112(2):122-126. doi: 10.1007/s00347-014-3179-9

7. Dupuy-Dutemps L, Bourguet J. Procede plastique de dacryocystorhinostomie et ses resultats. Ann Ocul J. 1921;158:241-246.

8. Balikoglu-Yilmaz M, Yilmaz T, Taskin U, Taskapili M, Akcay M, Oktay MF, et al. Prospective comparison of 3 dacryocystorhinostomy surgeries: external versus endoscopic versus transcanalicular multidiode laser. Ophthalmic Plast Reconstr Surg. 2015;31(1):13-18. doi: 10.1097/IOP.0000000000000159

9. Islam MR, WadudSA, Akhanda AH, RahmanMS, Habibullah M, Kabir MS, et al. Outcome of Transcanalicular Endolaser and External Dacryocystorhinostomy in Chronic Dacryocystitis. Mymensingh Med J. 2018;27(4):673-678.

10. McClintic SM, Yoon MK, Bidar M, Dutton JJ, Vagefi MR, Kersten RC. Tissue necrosis following diode laser-assisted transcanalicular dacryocystorhinostomy Ophthalmic Plast Reconstr Surg. 2015;31(1):18-22. doi: 10.1097/IOP.0000000000000045

11. Drnovsek-Olup B, Beltram M. Transcanalicular diode laserassisted dacryocystorhinostomy. Indian J Ophthalmol. 2010;58(3):213-217. doi: 10.4103/0301-4738.62646

12. Tuladhar S, Adhikari S, Bhattarai BK. Effectiveness of sedation in dacryocystorhinostomy surgery. Nepal J Ophthalmol. 2009;1(1):25-31.
13. Mushtaq A. Dacryocystorhinostoy with and with- out intubation. Ophthalmol 1992;8:39-42.

14. Shahraki K, Makateb A, Shirzadi K, Khosravifard K. Frequency of Bacterial Samples from Patients with Chronic Acquired Nasolacrimal Duct Obstruction. Med Arch. 2016;70(6):433-436. doi: 10.5455/ medarh.2016.70.433-436

15. Zuhair Al-Asadi S, Muhammed Al-Abbasy A. Efficacy of diode laser transcanalicular dacryocystorhinostomy for the treatment of acquired nasolacrimal duct obstruction. Gomal J Med Sci. 2011;9(2):64-68.

16. Mishra D, Bhushan P, Sinha BP, Bhaskar G, Rao R. External dacryocystorhinostomy conventional surgery versus Pawar implant: A comparative study. Indian J Opht- halmol 2019;67(7):1143-1147. doi: 10.4103/ijo.IJO_1889_18

17. Koch, K.R., Cursiefen, C., Heindl, L.M. Transcanalicular Laser Dacryocystorhinostomy: One-Year-Experience in the Treatment of Acquired Nasolacrimal Duct Obstructions. Klin Monbl Augenheilkd 2016;233(2):182-186. doi: 10.1055/ s-0041-106653

18. Uludag, G., Yeniad, B., Ceylan, E., Yildiz-Tas, A., KozerBilgin, L. Outcome comparison between transcanalicular and external dacryocystorhinostomy. Int J Ophthalmol. 2015;8(2):353-357. doi: 10.3980/j.issn.2222-3959.2015.02.25.

19. Ozcimen, M, Uysal IO, Eryilmaz MA, Kal A. Endocanalicular diode laser dacryocystorhinostomy for nasolacrimal duct obstruction: short term results of a new minimally invasive surgical technique. J Craniofac Surg. 2010;21(6):1932-1934. doi: 10.1097/SCS.0b013e3181f4eeb6

20. D'Ecclesia A, Cocchi RF, Giordano F, Mazzilli E Longo C, Laborante A. Endoscopic laser-assisted dacryocistorhinostomy DCR with the placement of a customised silicone and Teflon bicanalicular stent Endoscopic laser-assisted dacryocystorhinostomy (DCR). Clin Ter. 2014;165(6):391-394. doi: 10.7417/CT.2014.1779

21. Dogan, R, Meric A, Ozsutcu M, Yenigun A. Diode laserassisted endoscopic dacryocystorhinostomy: A comparison of three different combinations of adjunctive procedures. Eur Arch Otorhinolaryngol. 2013;270(8):2255-2261. doi: 10.1007/s00405-013-2351-1

22. Kaynak P, Ozturker C, Yazgan S, Karabulut GO, Akar S, Demirok A, et al. Transcanalicular diode laser assisted dacryocystorhinostomy in primary acquired nasolacrimal duct obstruction: 2-year follow up. Ophthal Plast Reconstr Surg. 2014;30(1):28-33 doi: 10.1097/01. iop.0000437533.66479.f0

23. Chan W, Selva D. Ostium shrinkage after endoscopic dacryocystorhinostomy. Ophthalmol. 2013;120:1693-1696. doi: 10.1016/j.ophtha.2013.01.024

24. Ali MJ, Psaltis AJ, Wormald PJ. Dacryocystorhinostomy ostium: parameters to evaluate and DCR ostium scoring. Clin Ophthalmol. 2014;8:2491-2499. doi: 10.2147/OPTH.S73998.

\section{Authors' Contribution:}

MA: Collected data and did manuscript writing. SAHN: Performed surgical procedure on selected patients and did proof reading of manuscript.

AA: Did analysis of data and contributed in manuscript writing.

MS: Contributed in the surgery of selected patients and contributed in manuscript writing. 